\title{
Cardiomyocyte injury induced by hemodynamic cardiac stress: differential
}

release of cardiac biomarkers

Affan Irfan, MD ${ }^{1,2}$; Tobias Reichlin, MD ${ }^{1,3}$; Raphael Twerenbold, MD ${ }^{1,4}$; Clarissa

Fischer, MD; Paola Ballarino, MD5; Berit Nelles, MD¹; Karin Wildi MD ${ }^{1}$, Christa Zellweger, MD¹, Maria Rubini Gimenez, MD ${ }^{1,6}$; Mira Mueller, MD"; Philip Haaf, MD¹, Andreas Fischer, $\mathrm{MS}^{1}$, Heike Freidank, MD ${ }^{7}$, Stefan Osswald, $\mathrm{MD}^{1}$ and Christian Mueller, $\mathrm{MD}^{1}$

${ }^{1}$ Department of Cardiology, University Hospital Basel, Switzerland; ${ }^{2}$ Department of Cardiology, University of Louisville, KY, USA; ${ }^{3}$ Cardiovascular Division, Department of Medicine, Brigham and Women's Hospital and Harvard Medical School, Boston, MA, USA. ${ }^{4}$ Universitäres Herz-Zentrum Bad Krozingen, Germany; ${ }^{5}$ Emergency Department, Genova, Italy, ${ }^{6}$ Servicio de Urgencias y Pneumologia, CIBERES ISC III, Hospital del Mar - Institut Municipal d'Investigació Mèdica, Barcelona, Spain; ${ }^{7}$ Laboratory Medicine, University Hospital Basel, Switzerland.

${ }^{1-7}$ This author takes responsibility for all aspects of the reliability and freedom from bias of the data presented and their discussed interpretation

Short title: Hemodynamic cardiac stress induced cardiomyocyte injury

Word count: 1200

\section{Corresponding author:}

Professor Dr. Christian Mueller, Department of Cardiology, University Hospital Basel, Petersgraben 4, CH-4031 Basel, Switzerland,

Tel: 00-41-612655826, Fax: 00-41-612655353

E-Mail: chmueller@uhbs.ch.

Key words: cardiomyocyte injury, cardiac stress, BNP, troponin 


\section{Abstract (250 words)}

Objective: We explored whether hemodynamic cardiac stress leads to a differential release of cardiomyocyte injury biomarkers, used in the diagnosis of acute myocardial infarction (AMI).

Methods: In an observational international multicenter study, we enrolled 831 unselected patients presenting with symptoms suggestive of AMI to the emergency department. The final diagnosis was adjudicated by two independent cardiologists. Hemodynamic cardiac stress was quantified by levels of B-type natriuretic peptide (BNP). Spearman's rho correlation was used to analyze the correlations between BNP and high-sensitivity cardiac troponin T (hs-cTnT), Siemens cTnl-Ultra (cTnlultra), CK-MB and Myoglobin. Patients were categorized according to the extent of hemodynamic cardiac stress as quantified by BNP tertiles.

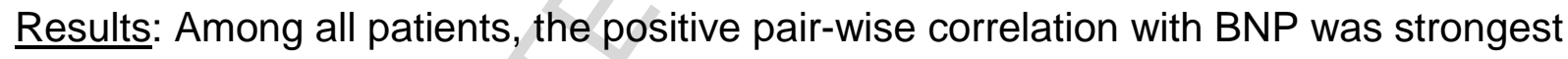
with hs-cTnT and cTnl-ultra ( $r=0.58$ and 0.50 , respectively), moderate for Myoglobin $(r=0.43)$, and weakest with CK-MB $(r=0.25 ; p<0.001$ for each). Similar pattern of correlations was also observed among AMI patients. Among patients diagnosed with non-cardiac cause of chest pain $(n=385,46 \%)$ and cardiac but non-coronary $(n=109$, 13\%), BNP had significant positive correlations with hs-cTnT, cTnl-ultra and Myoglobin $(p<0.05)$, but not wiht CK-MB $(p=N S)$. A similar pattern of stronger correlation between BNP and hs-cTnT, cTnl-ultra and Myoglobin as compared to that with $\mathrm{CK}-\mathrm{MB}$ was also observed within the higher BNP tertile range. There was no correlation between BNP and other biomarkers within the $1^{\text {st }}$ BNP tertile group.

Conclusion: Hemodynamic cardiac stress, as quantified by BNP, as a likely cause of cardiomyocyte injury, is more closely reflected by concentrations of hs-cTnT, cTnlultra and Myoglobin than CK-MB. 


\section{Introduction}

Biomarkers of cardiomyocyte injury, cardiac troponin T and I (cTnT and cTnl), are integral to the diagnosis of acute myocardial infarction (AMI) ${ }^{1,2}$. Although these markers have been used clinically for decades, the detailed triggers and mechanisms of their release are still incompletely understood. A better understanding of their triggers could potentially help make better use of these markers of cardiomyocyte injury in the evaluation of acute chest pain. Therefore we explored the association of hemodynamic cardiac stress, as quantified by B-type natriuretic peptide (BNP) and $\mathrm{N}$-terminal proBNP levels (NT-proBNP) ${ }^{3-6}$, with levels of high-sensitivity cTnT, cTnl, myoglobin, and CK-MB among chest pain patients presenting to the Emergency Department (ED).

\section{Methods}

The Advantageous Predictors of Acute Coronary Syndromes Evaluation (APACE) study is an ongoing prospective, international, multicenter study designed and coordinated by the University Hospital Basel, Switzerland. (ClinicalTrials.gov Identifier: NCT00470587). From April 2006 to June 2009, consecutive patients who presented to the ED with symptoms suggestive of AMI, within the last 12 hours were recruited. Patients with terminal kidney failure requiring dialysis were excluded. The study was conducted according to the principles of the Declaration of Helsinki and approved by the local ethics committee at each participating institution. Written informed consent was obtained from all patients. To determine the final diagnosis for each chest pain patient, two independent cardiologists reviewed all available medical records to 90-day follow-up. In situations of diagnostic disagreement, cases were reviewed and adjudicated in conjunction with a third cardiologist. The details of the predefined criteria for diagnosis are given in Appendix A. 


\section{Biochemical Analysis}

Blood samples were collected at the time of patient's presentation to ED. After centrifugation, samples were frozen at $-80^{\circ} \mathrm{C}$ until they were assayed in a blinded fashion in a dedicated core laboratory. The high-sensitivity cardiac troponin T (hscTnT) assay was performed with the use of the Elecsys 2010 system (Roche Diagnostics). Limit of Detection has been determined to be $0.005 \mu \mathrm{g} / \mathrm{l}$, an imprecision corresponding to $10 \%$ coefficient of variation (CV) was reported at $0.013 \mu \mathrm{g} / \mathrm{l}$ and the 99th-percentile of a healthy reference population at $0.014 \mu \mathrm{g} / \mathrm{l}^{7}$. The Siemens Ultra cardiac troponin I (cTnl-ultra) assay was performed with the use of the ADVIA Centaur immunoassay system (Siemens). LoD has been determined to be 0.006 $\mu \mathrm{g} / \mathrm{l}$, a $10 \% \mathrm{CV}$ was reported at $0.030 \mu \mathrm{g} / \mathrm{l}$ and the 99 th-percentile cutoff point of 0.04 $\mu \mathrm{g} / \mathrm{I}^{8}$. BNP was measured using the AxSYM BNP assay (Abbott Laboratories, Abbott Park, III). The analytical range as reported by the manufacturer extends from 15 to 20,000 pg/mL for the AxSYM assay ${ }^{9}$. NT-proBNP was measured using the Elecsys 2010 system (Roche Diagnostics). The CK-MB mass was measured using the Elecsys CK-MB immunoassay (Roche Diagnostics, Rotkreuz, Switzerland) with a measuring range of $0.1-500 \mathrm{ng} / \mathrm{mL}$ and a coefficient of variation of $2.1-3.5 \%$ at 5.6 $\mathrm{ng} / \mathrm{mL}$. Myoglobin mass was measured using the Elecsys Myoglobin immunoassay (Roche Diagnostics, Rotkreuz, Switzerland) with a measuring range of 21-3'000 $\mathrm{ng} / \mathrm{mL}$ and a coefficient of variation (intermediate precision) of $1.8-2.3 \%$ at $36 \mathrm{ng} / \mathrm{mL}$. 


\section{Results and Discussion}

A total of 831 patients had BNP, CTnT, myoglobin, and CK-MB levels measured at presentation; and cTnl-ultra was available in 807 (97\%) patients. Median time for onset of chest pain to ED presentation was 6 hours. Table 1 shows the baseline characteristics of patients.

The major novel finding of our study is that the positive pair-wise correlation with BNP was strongest for hs-cTnT and cTnl-ultra ( $r=0.58$ and 0.50 , respectively), followed by that with Myoglobin ( $r=0.43)$, and was weakest for CK-MB ( $r=0.25$; $\mathrm{p}<0.001$ for each) (Figure 1). Our study extends the new guidelines Class III recommendation (and not measuring CK-MB and myoglobin for the diagnosis of $\mathrm{Ml})^{2}$ including when detecting myocardial ischemia during hemodynamic stress. These significant pair-wise correlation persisted even when the cohort was subdivided into those who presented early ( $\leq 6$ hours) and late ( $>6$ hours). (Appendix B).

When stratified according to the BNP tertiles (Table $2 \mathrm{~A}$ ), no biomarker significant correlated with BNP ( $p>0.05)$ among patients within the first BNP tertile group. When stratified according to the BNP tertiles and time since onset of chest pain (Appendix B), similar results were seen in first and third tertile, but interestingly in the 2nd tertile, the hs-cTnT and cTnl-ultra significantly correlated with BNP only in those who presented early ( $\leq 6$ hours) but not in late presenters ( $>6$ hours).

We also confirmed the finding of increased hemodynamic stress among AMI patients as highlighted by increased BNP ${ }^{10}$. In AMI, impaired blood flow results in ischemia, infarction and increased hemodynamic stress. Figure 2 shows the box plot levels of four investigational markers according to the final diagnosis. Another major finding of our study is that when stratified according the five groups of final adjudicated diagnosis (Table 2 B), CK-MB was the only marker that did not significantly correlate with BNP among cardiac but non-coronary and non-cardiac 
cause of chest pain patients. The strong correlation with BNP for hs-cTnT and cTnlultra persisted even in patients adjudicated to have non-cardiac causes of chest pain.

The 3 biomarkers for cardiomyocyte injury (cTnT, cTnl, myoglobin, and CKMB) significantly correlated with each other in all patients and within each subgroup by BNP tertiles, final diagnoses and onset of chest pain.

Overall, these findings were confirmed in the subgroup of patients $(n=502)$ in which also levels of NT-proBNP were available and used for the quantification of hemodynamic cardiac stress. (Supplementary Table S1 and S2 and Figure S2).

The sequence of events resulting in cardiomyocyte injury is unclear, however hemodynamic cardiac stress itself might likely be the cause of cardiomyocyte injury, indicating it is more common than previously thought and not restricted to acute cardiac conditions. The phenomenon of hemodynamic cardiac stress induced cardiomyocyte injury has first been described in patients with acute heart failure ${ }^{11,12}$. We can only hypothesize why increased hemodynamic cardiac stress leads to a predominate release of $\mathrm{CTnT}$ and I, as assessed by sensitive assays, and myoglobin rather than CK-MB. Potential reasons include the different mechanism of release, release kinetics including the half lives of the markers (13), different levels of injury necessary to result in the loss of these structural cardiomyocyte proteins and different reflection of reversible and irreversible injury $(1,14,15)$. Another possible explanation is the relative difference in the tissue concentrations between the different biomarkers. Our data highlight that this seems to be a graded and possible continuous phenomenon.

Several limitations of the study merit consideration. First, the vast majority of patients were Caucasians and terminal renal failure patients were excluded. Therefore, the impact of race and terminal renal failure on biomarker association could not be determined. Second, as an observational study, we are unable to test 
the clinical benefit nor establish a causal link between BNP or NT-proBNP with cardiomyocyte injury biomarkers (ie whether hemodynamic stress occurred before or after index event). Third, the onset of chest pain time is the only kinetic measure that was explored in this study. Fourth, heart failure is known to lead to both cTn and BNP elevations, and its potential as a confounding factor was not studied. History of heart failure was not recorded in the case report form. However, the results of the study were unchanged even when patients on diuretics, $n=214(26 \%)$, were removed from the analyses. Fifth, there were several other factors (mainly those found significantly different among the three tertile groups as in table 1, such as age, CAD etc) that are potential confounders and were not assessed.

\section{Conclusion}

Hemodynamic cardiac stress, as quantified by BNP (or NT-proBNP) levels, is more closely reflected by concentrations of hs-cTnT, cTnl-ultra and Myoglobin than CK-MB. Our study findings support the use of $\mathrm{cTnl}$ and $\mathrm{T}$ for the detection of myocardial injury during increased hemodynamic stress. Furthermore, increased hemodynamic stress and myocardial injury is commonly seen among acute chest pain patients, even among those diagnosed with a non-cardiac cause of chest pain. Further research is needed to explore the kinetic differences in BNP and cTn. 


\section{Acknowledgements}

We thank the patients who participated in the study, the staff of the emergency department, the laboratory technicians, and particularly Michael Freese, Claudia Stelzig, Esther Garrido, Irina Klimmeck, Melanie Wieland, Janine Voegele, Kirsten Hochholzer, Beate Hartmann, and Fausta Chiaverio for their most valuable efforts.

\section{Conflict of interest}

This study was supported by research grants from the Swiss National Science Foundation, the Swiss Heart Foundation, Abbott, BRAHMS, Nanosphere, 8sense, Roche, Siemens, and the Department of Internal Medicine, University Hospital Basel. Prof. Mueller has received research grants from the Swiss National Science Foundation, the Swiss Heart Foundation, the Stiftung für kardiovaskuläre Forschung Basel, Abbott, Alere, Beckman Coulter, Biomerieux, Brahms, Nanosphere, 8sense, Critical Diagnostics, Roche, Siemens, Singulex and the Department of Internal Medicine of the University Hospital Basel, as well as speaker/consulting honoraria from Abbott, Alere, BG medicine, Biomerieux, BRAHMS, Radiometer, Roche, Novartis, Siemens and Singulex. We disclose that Dr. Reichlin has received research grants from the Swiss National Science Foundation (PASMP3-136995), the Swiss Heart Foundation, the University of Basel, the Professor Max Cloetta Foundation and the Department of Internal Medicine, University Hospital Basel as well as speakers honoraria from Brahms and Roche. All other authors declare that they have no conflict of interest with this study. The hs-cTn assays were donated by their manufactures, who had no role in the design of the study, the analysis of the data, the preparation of the manuscript and its submission to publication. 


\section{References}

1. Thygesen K, Mair J, Katus H, Plebani M, Venge P, Collinson P, Lindahl B, Giannitsis E, Hasin Y, Galvani M, Tubaro M, Alpert JS, Biasucci LM, Koenig W, Mueller C, Huber K, Hamm C, Jaffe AS. Recommendations for the use of cardiac troponin measurement in acute cardiac care. Eur Heart J 2010;31:2197-204.

2. Amsterdam EA, Wenger NK, Brindis RG, Casey DE, Jr., Ganiats TG, Holmes DR, Jr., Jaffe AS, Jneid H, Kelly RF, Kontos MC, Levine GN, Liebson PR, Mukherjee D, Peterson ED, Sabatine MS, Smalling RW, Zieman SJ. 2014 AHA/ACC Guideline for the Management of Patients With Non-ST-Elevation Acute Coronary Syndromes: A Report of the American College of Cardiology/American Heart Association Task Force on Practice Guidelines. $J$ Am Coll Cardiol 2014.

3. Levin ER, Gardner DG, Samson WK. Natriuretic peptides. N Engl J Med 1998;339:321-8.

4. Suzuki T, Yamazaki T, Yazaki Y. The role of the natriuretic peptides in the cardiovascular system. Cardiovasc Res 2001;51:489-94.

5. Maeder MT, Mariani JA, Kaye DM. Hemodynamic determinants of myocardial B-type natriuretic peptide release: relative contributions of systolic and diastolic wall stress. Hypertension 2010;56:682-9.

6. Marcus LS, Hart D, Packer M, Yushak M, Medina N, Danziger RS, Heitjan DF, Katz SD. Hemodynamic and renal excretory effects of human brain natriuretic peptide infusion in patients with congestive heart failure. A double-blind, placebo-controlled, randomized crossover trial. Circulation 1996;94:3184-9.

7. Giannitsis E, Kurz K, Hallermayer K, Jarausch J, Jaffe AS, Katus HA. Analytical validation of a high-sensitivity cardiac troponin T assay. Clin Chem 2010;56:254-61.

8. Apple FS, Smith SW, Pearce LA, Ler R, Murakami MM. Use of the Centaur TnI-Ultra assay for detection of myocardial infarction and adverse events in patients presenting with symptoms suggestive of acute coronary syndrome. Clin Chem 2008;54:723-8.

9. Mueller T, Gegenhuber A, Poelz W, Haltmayer M. Preliminary evaluation of the AxSYM B-type natriuretic peptide (BNP) assay and comparison with the ADVIA Centaur BNP assay. Clin Chem 2004;50:1104-6.

10. Mayr A, Mair J, Schocke M, Klug G, Pedarnig K, Haubner BJ, Nowosielski M, Grubinger T, Pachinger O, Metzler B. Predictive value of NT-pro BNP after acute myocardial infarction: relation with acute and chronic infarct size and myocardial function. Int $J$ Cardiol 2011;147:118-23.

11. Januzzi JL, Jr., Filippatos G, Nieminen M, Gheorghiade M. Troponin elevation in patients with heart failure: on behalf of the third Universal Definition of Myocardial Infarction Global Task Force: Heart Failure Section. Eur Heart J 2012.

12. Pascual-Figal DA, Casas T, Ordonez-Llanos J, Manzano-Fernandez S, Bonaque JC, Boronat M, Munoz-Esparza C, Valdes M, Januzzi JL. Highly sensitive troponin T for risk stratification of acutely destabilized heart failure. Am Heart J 2012;163:1002-10. 
Table 1 shows the baseline characteristics of all patients and also according to the BNP tertiles. The medications are those which the patients were taking at the time of admission.

\begin{tabular}{|c|c|c|c|c|c|}
\hline \multicolumn{6}{|l|}{ Baseline characteristics $(n=831)$} \\
\hline \multirow{2}{*}{ Factor } & \multirow{2}{*}{ All patients } & \multicolumn{3}{|c|}{ BNP tertiles } & \multirow{2}{*}{$\begin{array}{c}p \\
\text { value }\end{array}$} \\
\hline & & $1 \mathrm{st}(\leq 38 \mathrm{pg} / \mathrm{ml})$ & 2nd $(38.01-132 \mathrm{pg} / \mathrm{ml})$ & $3 \mathrm{rd}(\geq 132.01 \mathrm{pg} / \mathrm{ml})$ & \\
\hline Age (in years)* & $64[51-75]$ & $51[43-61]$ & $65[54-74]$ & $75[65-82]$ & $<0.01$ \\
\hline Male gender & $565(68)$ & $203(73)$ & $188(68)$ & $174(63)$ & 0.04 \\
\hline BMI* & $26[24-29]$ & $26[24-30]$ & $27[24-30]$ & $26[24-29]$ & 0.14 \\
\hline $\begin{array}{l}\text { Glomerular Filtration Rate } \\
\left(\mathrm{ml} / \mathrm{min} / \mathrm{m}^{2}\right)^{*}\end{array}$ & $90[73-107]$ & $101[88-114]$ & $90[75-105]$ & $76[58-95]$ & $<0.01$ \\
\hline Coronary Artery Disease & $324(39)$ & $56(20)$ & $105(38)$ & $163(59)$ & $<0.01$ \\
\hline Previous Myocardial infarction & $218(26)$ & $35(13)$ & $70(25)$ & $113(41)$ & $<0.01$ \\
\hline Hypertension & $524(63)$ & $125(45)$ & $179(65)$ & $220(79)$ & $<0.01$ \\
\hline Hypercholestrolemia & $343(41)$ & $92(31)$ & $122(44)$ & $129(47)$ & $<0.01$ \\
\hline Diabetes mellitus & $141(17)$ & $30(11)$ & $48(18)$ & $63(23)$ & 0.01 \\
\hline Stroke & $55(7)$ & $4(1)$ & $15(5)$ & $36(13)$ & $<0.01$ \\
\hline Lung disease & $93(11)$ & $32(12)$ & $26(9)$ & $35(13)$ & 0.48 \\
\hline Peripheral Artery Disease & $62(8)$ & $5(2)$ & $19(7)$ & $38(14)$ & $<0.01$ \\
\hline Chronic Renal insufficiency & $88(11)$ & $5(2)$ & $15(5)$ & $68(25)$ & $<0.01$ \\
\hline Aspirin & $338(41)$ & $74(27)$ & $123(45)$ & $141(51)$ & $<0.01$ \\
\hline${ }^{\Delta}$ ACE or ARB & $325(39)$ & $66(24)$ & $98(36)$ & $161(58)$ & $<0.01$ \\
\hline Beta-Blocker & $329(40)$ & $57(21)$ & $99(36)$ & $173(63)$ & $<0.01$ \\
\hline Ca antagonist & $139(17)$ & $29(10)$ & $47(17)$ & $63(23)$ & $<0.01$ \\
\hline Statin & $400(48)$ & $81(29)$ & $146(53)$ & $173(63)$ & $<0.01$ \\
\hline Diuretic & $214(26)$ & $33(12)$ & $59(21)$ & $122(44)$ & $<0.01$ \\
\hline
\end{tabular}

*Median[InterQuartile Range] ${ }^{\Delta}$ ACE or ARB: Angiotensin Converting Enzyme Inhibitor or Angiotensin Receptor Blocker 
Supplementary Appendix Table S1 shows the baseline characteristics of all patients and also according to the N-terminal pro B-type Natriuretic peptide (NT-proBNP) tertiles. The medications are those, which the patients were taking at the time of admission.

\begin{tabular}{|c|c|c|c|c|c|}
\hline \multicolumn{6}{|l|}{ Baseline characteristics $(n=502)$} \\
\hline \multirow{2}{*}{ Factor } & \multirow{2}{*}{ All patients } & \multicolumn{3}{|c|}{ NT-proBNP tertiles } & \multirow{2}{*}{$\begin{array}{c}\mathrm{p} \\
\text { value }\end{array}$} \\
\hline & & $1 \mathrm{st}(\leq 87 \mathrm{pg} / \mathrm{ml})$ & 2nd $(87.1-408.2 \mathrm{pg} / \mathrm{ml})$ & $3 \mathrm{rd}(\geq 408.3 \mathrm{pg} / \mathrm{ml})$ & \\
\hline Age (in years)* & $65[52-76]$ & $51[43-60]$ & $66[56-77]$ & $76[69-82]$ & $<0.01$ \\
\hline Male gender & $332(66)$ & $124(74)$ & $104(62)$ & $104(63)$ & 0.04 \\
\hline BMI* & $26[24-29]$ & $26[23-29]$ & $27[24-29]$ & $26[24-29]$ & 0.15 \\
\hline $\begin{array}{l}\text { Glomerular Filtration Rate } \\
\left(\mathrm{ml} / \mathrm{min} / \mathrm{m}^{2}\right)^{*}\end{array}$ & 93 [75 - 109] & 104 [92 - 120] & $92[77-105]$ & $75[59-94]$ & $<0.01$ \\
\hline Coronary Artery Disease & $186(37)$ & $32(19)$ & $73(44)$ & $81(49)$ & $<0.01$ \\
\hline Previous Myocardial infarction & $141(28)$ & $21(13)$ & $51(31)$ & $69(41)$ & $<0.01$ \\
\hline Hypertension & $310(62)$ & $64(38)$ & $111(67)$ & $135(81)$ & $<0.01$ \\
\hline Hypercholestrolemia & $218(43)$ & $59(35)$ & $76(46)$ & $83(50)$ & 0.02 \\
\hline Diabetes mellitus & $81(16)$ & $13(8)$ & $26(16)$ & $42(25)$ & $<0.01$ \\
\hline Stroke & $36(7)$ & $2(1)$ & $9(5)$ & $25(15)$ & $<0.01$ \\
\hline Lung disease & $61(12)$ & $22(13)$ & $17(10)$ & $22(13)$ & 0.63 \\
\hline Peripheral Artery Disease & $37(7)$ & $5(3)$ & $10(6)$ & $22(13)$ & $<0.01$ \\
\hline Chronic Renal insufficiency & $50(10)$ & $2(1)$ & $6(4)$ & $42(25)$ & $<0.01$ \\
\hline Aspirin & $202(40)$ & $43(26)$ & $77(46)$ & $82(49)$ & $<0.01$ \\
\hline${ }^{\Delta}$ ACE or ARB & $325(39)$ & $38(23)$ & $72(43)$ & $97(58)$ & $<0.01$ \\
\hline Beta-Blocker & $204(41)$ & $30(18)$ & $76(46)$ & $98(59)$ & $<0.01$ \\
\hline Ca antagonist & $87(17)$ & $19(11)$ & $34(20)$ & $34(20)$ & 0.04 \\
\hline Statin & $183(37)$ & $43(26)$ & $66(40)$ & $74(44)$ & $<0.01$ \\
\hline Diuretic & $141(28)$ & $16(10)$ & $44(26)$ & $81(49)$ & $<0.01$ \\
\hline
\end{tabular}

*Median[InterQuartile Range] ${ }^{\Delta}$ ACE or ARB: Angiotensin Converting Enzyme Inhibitor or Angiotensin Receptor Blocker 
Table 2 shows the correlation between B-type Natriuretic peptide (BNP) and highsensitive cardiac troponin-T (hs-cTnT), Siemens Ultra cardiac troponin I (cTnl-ultra), Creatine Kinase-Myocardial Band (CK-MB) and Myoglobin as bivariate analysis with spearman correlation; according to BNP tertiles (A) and final adjudicated diagnosis (B).

Table A

\begin{tabular}{|c|c|c|c|c|c|c|c|c|}
\hline \multirow{3}{*}{ Correlation with BNP and: } & \multirow{2}{*}{\multicolumn{2}{|c|}{ All patients }} & \multicolumn{6}{|c|}{ BNP tertiles } \\
\hline & & & \multicolumn{2}{|c|}{$\begin{array}{c}1 \mathrm{st} \\
(\leq 38 \mathrm{pg} / \mathrm{ml})\end{array}$} & \multicolumn{2}{|c|}{$\begin{array}{c}\text { 2nd } \\
(>38-132 \mathrm{pg} / \mathrm{ml})\end{array}$} & \multicolumn{2}{|c|}{$\begin{array}{c}3 \mathrm{rd} \\
(\geq 132.01 \mathrm{pg} / \mathrm{ml}\end{array}$} \\
\hline & $r$ & $p$ value & $r$ & $p$ value & $r$ & $p$ value & $r$ & $p$ value \\
\hline Hs-cTnT & 0.58 & $<0.01$ & - & NS & 0.16 & 0.01 & 0.41 & $<0.01$ \\
\hline cTnl-ultra & 0.50 & $<0.01$ & - & NS & - & NS & 0.41 & $<0.01$ \\
\hline CK-MB & 0.28 & $<0.01$ & - & NS & - & NS & 0.24 & $<0.01$ \\
\hline Myoglobin & 0.43 & $<0.01$ & - & NS & 0.14 & 0.03 & 0.28 & $<0.01$ \\
\hline
\end{tabular}

Table B

\begin{tabular}{|c|c|c|c|c|c|c|c|c|c|c|}
\hline \multirow{3}{*}{$\begin{array}{l}\text { Correlation with } \\
\text { BNP and: }\end{array}$} & \multicolumn{10}{|c|}{ Final Adjudicated diagnosis } \\
\hline & \multicolumn{2}{|c|}{$\begin{array}{c}\text { Acute } \\
\text { Myocardial } \\
\text { Infarction }\end{array}$} & \multicolumn{2}{|c|}{$\begin{array}{l}\text { Unstable } \\
\text { Angina }\end{array}$} & \multicolumn{2}{|c|}{$\begin{array}{l}\text { Cardiac but } \\
\text { non- } \\
\text { coronary }\end{array}$} & \multicolumn{2}{|c|}{ Non-cardiac } & \multicolumn{2}{|c|}{ Unknown } \\
\hline & $r$ & $\begin{array}{c}\mathrm{p} \\
\text { value }\end{array}$ & $r$ & $\begin{array}{c}\mathrm{p} \\
\text { value }\end{array}$ & $r$ & $\begin{array}{c}\mathrm{p} \\
\text { value }\end{array}$ & $r$ & $\begin{array}{c}\mathrm{p} \\
\text { value }\end{array}$ & $r$ & $\begin{array}{c}\mathrm{p} \\
\text { value }\end{array}$ \\
\hline Hs-cTnT & 0.45 & $<0.01$ & 0.37 & $<0.01$ & 0.55 & $<0.01$ & 0.43 & $<0.01$ & 0.46 & $<0.01$ \\
\hline Siemens-Ultra I & 0.36 & $<0.01$ & - & NS & 0.51 & $<0.01$ & 0.34 & $<0.01$ & 0.35 & $<0.01$ \\
\hline CK-MB & 0.20 & 0.02 & - & NS & - & NS & - & NS & 0.25 & 0.04 \\
\hline Myoglobin & 0.25 & $<0.01$ & 0.28 & $<0.01$ & 0.31 & $<0.01$ & 0.24 & $<0.01$ & 0.41 & $<0.01$ \\
\hline
\end{tabular}

r denotes spearman correlation, NS - Non-significant 
Supplementary Appendix

Table S2 shows the correlation between $\mathrm{N}$-terminal pro B-type Natriuretic peptide (NT-proBNP) and high-sensitivity cardiac troponin-T (hs-cTnT), Siemens Ultra cardiac troponin I (cTnl-ultra), Creatine Kinase-Myocardial Band (CK-MB) and Myoglobin as bivariate analysis with spearman correlation; according to Pro BNP tertiles (A) and final adjudicated diagnosis (B).

Table A

\begin{tabular}{|c|c|c|c|c|c|c|c|c|}
\hline \multirow{3}{*}{$\begin{array}{l}\text { Correlation with NT- } \\
\text { proBNP and: }\end{array}$} & \multirow{2}{*}{\multicolumn{2}{|c|}{ All patients }} & \multicolumn{6}{|c|}{ NT-proBNP tertiles } \\
\hline & & & \multicolumn{2}{|c|}{$\begin{array}{c}1 \mathrm{st} \\
(\leq 87 \mathrm{pg} / \mathrm{ml})\end{array}$} & \multicolumn{2}{|c|}{$\begin{array}{c}\text { 2nd } \\
(87.1-408.2 \mathrm{pg} / \mathrm{ml})\end{array}$} & \multicolumn{2}{|c|}{$\begin{array}{c}3 \mathrm{rd} \\
(\geq 408.3 \mathrm{pg} / \mathrm{ml})\end{array}$} \\
\hline & $r$ & $p$ value & $r$ & p value & $r$ & $p$ value & $r$ & $p$ value \\
\hline Hs-cTnT & 0.73 & $<0.01$ & 0.26 & $<0.01$ & 0.25 & 0.01 & 0.43 & $<0.01$ \\
\hline cTnl-ultra & 0.62 & $<0.01$ & - & NS & - & NS & 0.37 & $<0.01$ \\
\hline CK-MB & 0.40 & $<0.01$ & - & NS & - & NS & 0.19 & 0.01 \\
\hline Myoglobin & 0.54 & $<0.01$ & - & NS & - & NS & 0.28 & $<0.01$ \\
\hline
\end{tabular}

Table B

\begin{tabular}{|l|c|c|c|c|c|c|c|c|c|c|}
\hline \multirow{2}{*}{$\begin{array}{l}\text { Correlation with } \\
\text { NT-proBNP and: }\end{array}$} & \multicolumn{9}{|c|}{$\begin{array}{c}\text { Anal Adjudicated diagnosis } \\
\text { Myocardial } \\
\text { Infarction }\end{array}$} & \multicolumn{2}{|c|}{$\begin{array}{c}\text { Unstable } \\
\text { Angina }\end{array}$} & $\begin{array}{c}\text { Cardiac but } \\
\text { non- } \\
\text { coronary }\end{array}$ & \multicolumn{2}{c|}{ Non-cardiac } & \multicolumn{2}{c|}{ Unknown } \\
\hline & $\mathrm{r}$ & $\begin{array}{c}\mathrm{p} \\
\text { value }\end{array}$ & $\mathrm{r}$ & $\begin{array}{c}\mathrm{p} \\
\text { value }\end{array}$ & $\mathrm{r}$ & $\begin{array}{c}\mathrm{p} \\
\text { value }\end{array}$ & $\mathrm{r}$ & $\begin{array}{c}\mathrm{p} \\
\text { value }\end{array}$ & $\mathrm{r}$ & $\begin{array}{c}\mathrm{p} \\
\text { value }\end{array}$ \\
\hline Hs-cTnT & 0.44 & $<0.01$ & 0.55 & $<0.01$ & 0.65 & $<0.01$ & 0.62 & $<0.01$ & 0.41 & 0.01 \\
\hline Siemens-Ultra I & 0.35 & $<0.01$ & 0.42 & $<0.01$ & 0.53 & $<0.01$ & 0.46 & $<0.01$ & - & $\mathrm{NS}$ \\
\hline CK-MB & 0.23 & 0.03 & - & $\mathrm{NS}$ & 0.27 & 0.03 & 0.17 & 0.01 & - & $\mathrm{NS}$ \\
\hline Myoglobin & 0.34 & $<0.01$ & 0.30 & $<0.01$ & 0.38 & $<0.01$ & 0.37 & $<0.01$ & 0.42 & 0.01 \\
\hline
\end{tabular}

$r$ denotes spearman correlation, NS - Non-significant 
Figure 1 shows the scatter plots between log transformed B-type Natriuretic peptide (BNP) and A) Creatine Kinase-Myocardial Band (CK-MB), B) Myoglobin, C) highsensitivity cardiac troponin-T (hs-cTnT) and D) Siemens Ultra cardiac troponin I (cTnl-ultra).

Figure 2 shows the box plot levels of B-type Natriuretic peptide (BNP) and Creatine Kinase-Myocardial Band (CK-MB), Myoglobin, high-sensitivity cardiac troponin-T (hs$\mathrm{cTnT}$ ) and Siemens Ultra cardiac troponin I (cTnl-ultra) according to the final diagnosis. The boxes represent interquartile ranges, the horizontal line in each box represents the median, and the whiskers show the minimum and maximum values (excluding outliers that were more than 1.5 times the values represented at each end of the box).

\section{Supplementary Figure}

Figure $\mathrm{S} 1$ shows the scatter plots between log transformed $\mathrm{N}$-terminal pro B-type Natriuretic peptide (NT-proBNP) and A) Creatine Kinase-Myocardial Band (CK-MB), B) Myoglobin, C) high-sensitive cardiac troponin-T (hs-cTnT) and D) Siemens Ultra cardiac troponin I (cTnl-ultra). 

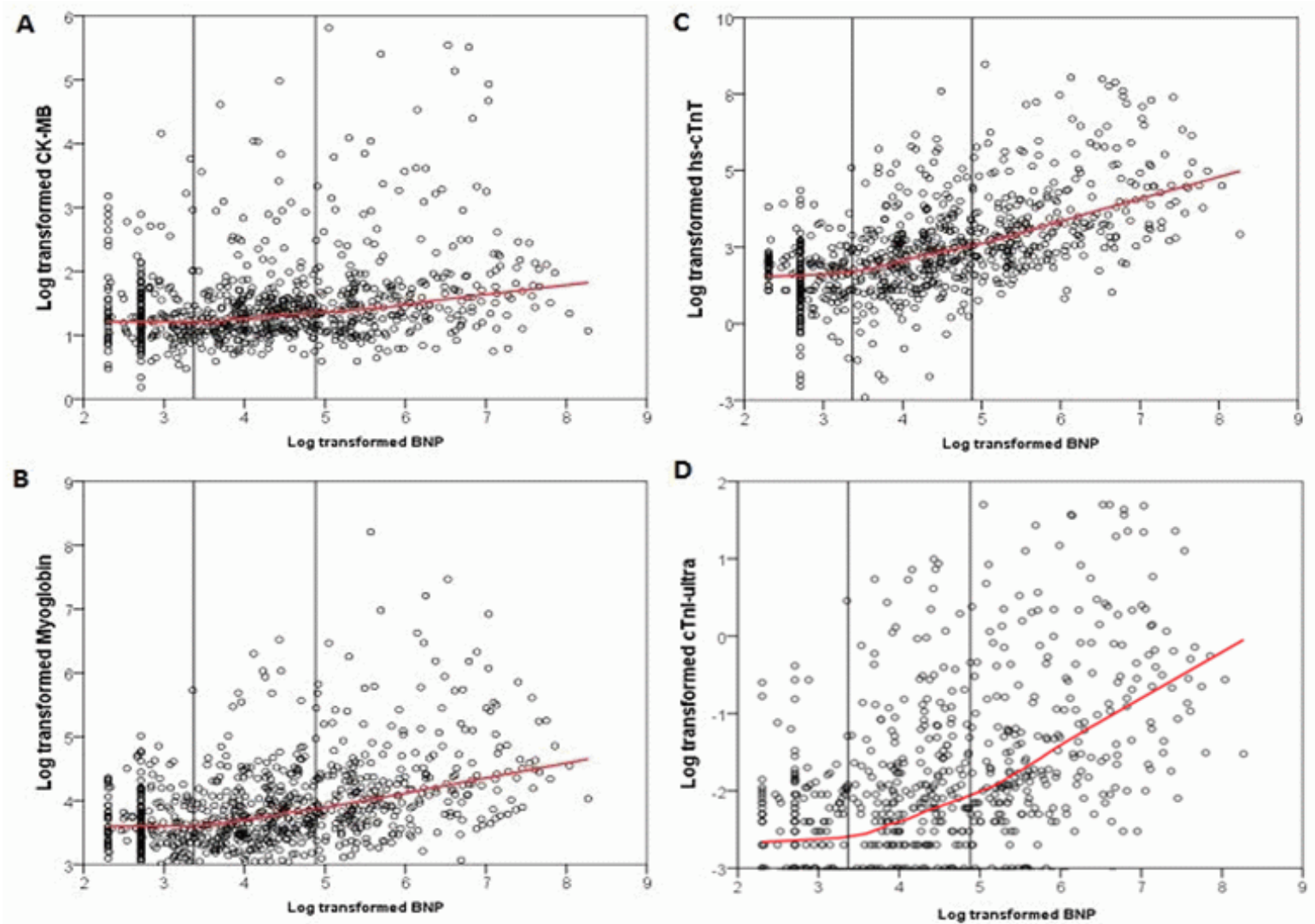

Fig. 1 


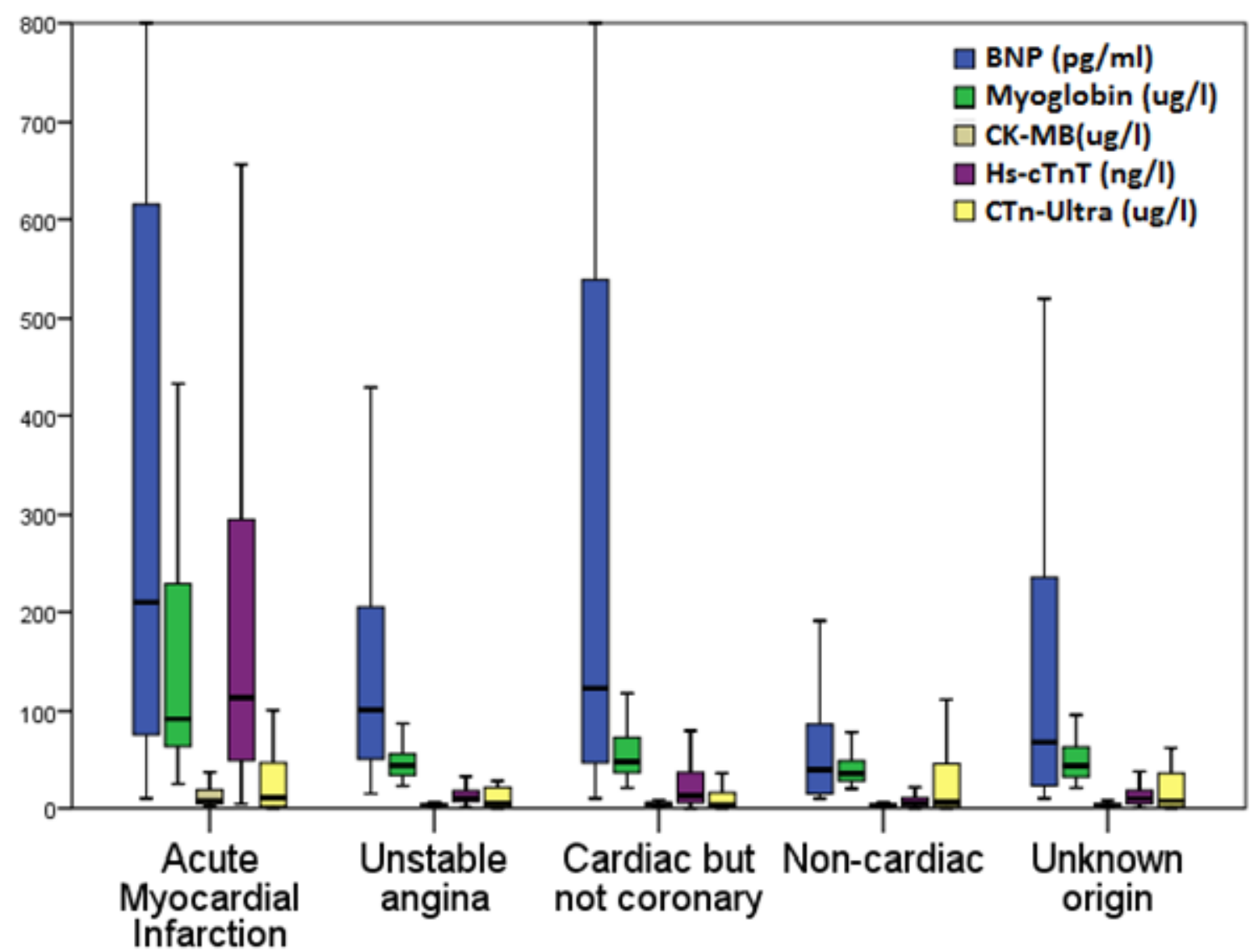

Fig. 2 


\section{Highlights}

- Hemodynamic cardiac stress, as quantified by BNP levels, is more closely reflected by concentrations of hs-cTnT, cTnl-ultra and Myoglobin than CK-MB.

- The strong correlation between the amount of hemodynamic cardiac stress and the amount of cardiomyocyte injury seems to be restricted to patients in the highest tertile

- Increased hemodynamic stress and myocardial injury is commonly seen among acute chest pain patients, even among those diagnosed with a non-cardiac cause of chest pain.

- Further research is needed to explore the kinetic differences in BNP and troponin 